\title{
Potato rhamnogalacturonan I reduces colon cancer cell proliferation via a galectin-3 independent mechanism
}

\author{
E. Maxwell, V. Morris, K. Waldron and N. Belshaw \\ Institute of Food Research, Norwich, UK NR4 7UA
}

Modified pectin is known to have anti-metastatic effects in various cancer cell lines but the mechanisms remain unclear ${ }^{(1)}$. Although structurally complex, pectin extracts contain galactan rich regions of rhamnogalacturonan I (RGI), attached to a polygalacturonic acid (PGA) backbone. It has been proposed that galactan chains can bind and inhibit Galectin-3 (Gal3) ${ }^{(2)}$, a protein upregulated in cancer cells and known to drive numerous processes in carcinogenesis ${ }^{(3)}$. We previously showed that potato galactan (PG) binds specifically to Gal3, whilst potato RGI showed a lower affinity and PGA did not bind at all ${ }^{(4)}$.

In this study we investigated the effects of potato RGI, PG, and PGA on cell proliferation in the colon cancer cell lines DLD1 and HCT116 and determined the role of Gal3 in mediating these effects. Cells were treated with 0.2, 0.5 and $1 \mathrm{mg} / \mathrm{ml} \mathrm{RGI,} \mathrm{PG} \mathrm{and} \mathrm{PGA}$ (all Megazyme, Ireland) in quadruplicate for $48 \mathrm{~h}$ and the effects on cell proliferation were measured using WST cell proliferation reagent (Roche, UK). Five independent experiments were performed. Cell proliferation of both cells lines was significantly reduced in a dose-dependent manner by RGI (Fig.1 $p<0.001$ ), while PG and PGA were ineffective.

Both cell lines were transfected with 12nM Gal3-specific siRNA's or non-specific control siRNA using Hiperfect transfection reagent according to the manufacturer's instructions (all Qiagen, UK). After $24 \mathrm{~h}$ of transfection, cells were supplied with medium with or without RGI $(1 \mathrm{mg} / \mathrm{ml})$ for $48 \mathrm{~h}$ before analysis of cell proliferation or harvesting for RNA and protein extraction. Gal3 gene expression was quantified by qRT-PCR and protein expression by western blot. Transfection decreased steady-state levels of Gal3 mRNA by $90 \%$ and 80\% in DLD1 and HCT116 cells, respectively, compared with cells transfected with non-specific, control siRNA. Accordingly, Gal3 protein expression was decreased by $91 \%$ and $90 \%$, respectively. The reduction of Gal3 expression in DLD1 and HCT116 cells had no significant impact on the anti-proliferative effect of RGI (Fig. $2 p<0 \cdot 001$ ). In conclusion, the present study demonstrates that RGI fragments extracted from potato fibre inhibit proliferation of the colon cancer cell lines DLD1 and HCT116 in a Gal3-independent manner.

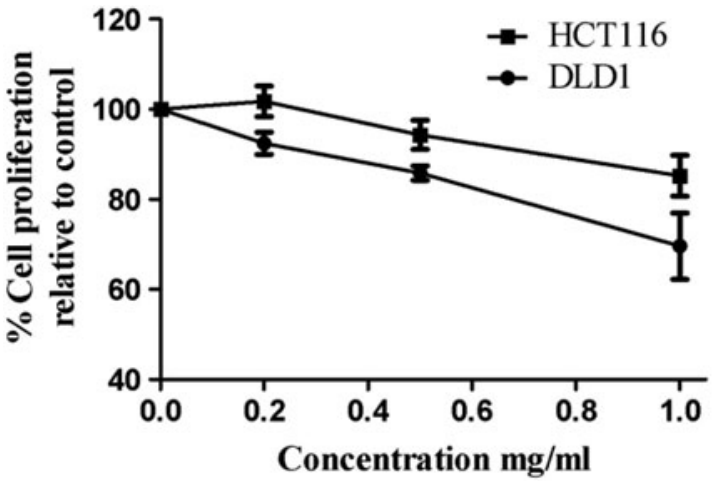

Fig. 1. Dose effect

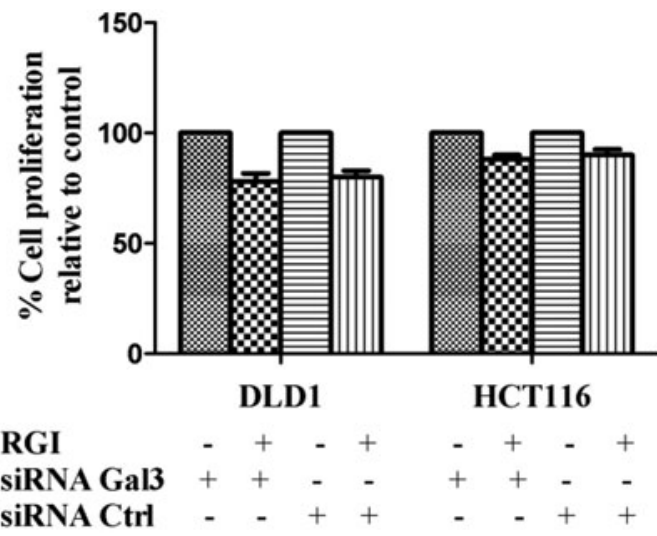

Fig. 2. siRNA

This work was supported by the International Pectin Producers Association via a BBSRC CASE studentship

1. Morris VJ, Belshaw NJ et al. (2013) Bioactive carbs and dietary fibre 1, 38-52.

2. Inohara H, Raz A (1994) Glycoconj J 11, 527-532.

3. Nangia-Makker P, Balan V et al. (2012)Methods Mol Biol 878, 251-266.

4. Gunning AP, Bongaerts RJM et al. (2009) Faseb J 23, 415-42. 